\title{
PERAN MUSTHAFA HUSEIN AL MANDILI DI PESANTREN MUSTHAFAWIYAH PURBA BARU (1915-1955)
}

Oleh:

Salman

Pristi Suhendro

\begin{abstract}
ABSTRAK
Penelitian yang berjudul Peran Musthafa Husein Al- Mandili di Pesantren Musthafawiyah Purba Baru ini bertujuan untuk mengetahui Peran Musthafa Husein Al-Mandili Di Pesantren Musthafawiyah Purba Baru 1912-1955. Kemudian, untuk mengetahui hambatan Musthafa Hesein Al Mandili dalam mendirikan Pesantren Musthafawiyah Purba Baru. Terahir, untuk mengetahui yang dilakukan Musthafa Husein Al Mandili untuk melanjutkan regenerasi kepemimpinan di Pesantren Musthafawiyah Purba Baru. Penelitian ini menggunakan metode Sejarah yang dikaji melalui empat tahapan yaitu, heuritik, verifikasi, interpretasi, dan historiografi. Peneliti melakukan penelitian buku (field research) melalui observasi dan dokumentasi. Penelitian ini dilaksanakan di Desa Purba Baru, Kecamatan Lembah Sorik Marapi, Kabupaten Mandailing Natal, Provinsi Sumatera Utara, Kode Pos 22952. Hasil penelitian ini menunjukan bahwa dalam kepemimpinan Syekh Musthafa Husein Nasution dimulai dari tahun 1912-1955 dengan jumlah santri 450 orang dan sarana / prasarana 9 lokal. Setelah Syekh Musthafa Husein meninggal, Kepemimpin Pondok Pesantren Musthafawiyah diwariskan kepada anak dan cucunya yaitu : 1) Kepemimpinan Pesantren Musthafawiyah Purba Baru dilanjutkan oleh anaknya yang bernama H.Abdullah Musthafa Nasution. Di masa kepemimpinan H. Abdollah Musthafa Nasution Pondok Pesantren Musthafawiyah Purba Baru mengalami kemajuan yang sangat pesat dengan jumlah santri 8.500 orang dari tahun 1955 1995 , 2) Setelah H. Abdullah Musthafa Nasution meninggal dunia estafet kepemimpinan Pondok Pesantren Musthawaiyah Purba Baru dilanjutkan oleh adik kandung beliau Drs. $\mathrm{H}$. Abdul Kholik Nasution yang juga merupakan putra Syekh Musthafa Husein Nasution Pendiri Pondok Pesantren Musthafawiyah Purba Baru, dan beliau memimpin Pondok Pesantren Mustfawiyah Purba Baru mulai tahun 1955-2003 dengan jum,lah santri 6.300 orang, 3) Kepemimpinan Pondok Pesantren Musthafawiyah Purba Baru dilanjutkan oleh cucu Syekh Musthafa Husein yaitu H. Mustafa Bakri Nasution yang merupakan putra dari H. Abdollah Musthafa Nasution, pada tahun 2003 sampai sekarang dengan jumlah santri 11.501 orang. Beliau mengikuti jejak ayahandanya yaitu dengan berusaha semaksimal mungkin untuk melanjutkan pembangunan Pondok Pesantren Musthafawiyah Purba Baru di segala bidang.
\end{abstract}

Kata kunci : Musthafa Husein Al-Mandili, Pesantren Musthafawiyah 


\section{I.PENDAHULUAN}

Purba Baru adalah salah satu desa di Kecamatan Mandailing Natal, Kabupaten Mandailing Natal.Desa ini terkenal berkat sebuah pesantren yang namanya sudah tidak asing dalam dunia pendidikan Islam di Indonesia.Pesantren tersebut bernama Musthafawiyah Purba Baru.Para santrinya berasal dari berbagai daerah, tidak hanya dari Mandailing Natal.Banyaknya peminat Pesantren Musthafawiyah Purba Baru dari luar Mandailing Natal menunjukkan pesantren tersebut kompeten dalam pendidikan Islam.Oleh karena itu, dari rahim Musthafawiyah Purba Baru telah lahir banyak generasi emas. Mereka yang berhasil menamatkan studi di sana dihormati ilmu keagamaannya. Sebagai akibatnya para lulusan itu diterima dengan sangat baik sebagai pendakwah atau kerap disapa 'ustadz' sekembalinya ke daerah asal.Kegemilangan yang diraih Pesantren Musthafawiyah Purba Baru itu tidak terlepas dari peran salah seorang pendirinya yakni Syekh Musthafa Husein Al-Mandili.

Syekh Musthafa dikenal sebagai guru agama yang juga mengajarkan para santrinya untuk mampumenjadi pengusaha, pedagang dan petani yang baik dan sukses. Suasana Pendidikan yang dikembangkan Syekh Musthafa di Purba Baru ini sangat menarik bagi masyarakat sekitar untuk mengirimkan anak-anaknya belajar di sana.Di pesantren Purba Baru ini para santri tidak hanya mendapatkan pelajaran agama saja tetapi bidang-bidang lain yang nantinya bisa jadi bekal di masa yang akan datang. Para santri laki-laki diwajibkan tinggal di gubuk-gubuk kecil di sekitar pesantren yang mendidik agar para santri mampu hidup mandiri.Suasana pendidikan seperti itu masih dipertahankan sampai saat ini.

Syekh Musthafa Husein lahir di Tano Bato, Kayu Laut pada tahun 1886 M/1303 $\mathrm{H}$ dengan nama kecil Muhammad Yatim dari pasangan $\mathrm{H}$. Husein Nasution dan $\mathrm{Hj}$. Halimah ayahnya seorang saudagar yang taat beragama. Keadaan masyarakat di Tano Bato saat itu sangat menyedihkan akibat perlakuan penjajah Belanda yang memberlakukan sistem tanam paksa bagi para petani. 
Di usia tujuh tahun, Syekh Musthafa bersekolah di Sekolah Dua, Kayu Laut. Setelah lima tahun tamat dan melajutkan belajar kepada Syekh Abdul Hamid di Huta Pungkut. Syekh Abdul Hamid merupakan kerabatnya sendiri yang menamatkan pendidikannya di Makkah. Pada Tahun 1900, Syekh Musthafa berkesempatan melanjutkan pendidikannya ke Mekkah, Saudi Arabia.

Syaikh Musthafa memulai Pesantren Musthafawiyah Purba Baru hanya dengan murid-murid yang turut serta dari Tano Bato yakni kira-kira 20 orang.Ia bersama 20 orang muridnya itu pindah ke Purba Baru karena banjir hebat yang melanda Tano Bato pada tahun 1915.Sesampainya di Purba Baru Syekh Musthafa tidak langsung mendirikan pesantren.Ia terlebih dahulu membangun masjid. Di masjid itulah para murid yang ia bawa belajar dengan cara berhalqah. Inilah salah satu hambatan yang dialami Syekh Musthafa Husein dalam memperluas pesantren Musthafawiyah Purba Baru karena muridnya masih sedikit.Jumlah murid yang masih sedikit itu merupakan tantangan awal setelah kepindahan dari Tano Bato.Namun perjuangan untuk tetap melancarkan dakwah Islam tidak surut dalam diri Syekh Musthafa Husein Al-Mandili.

Adapun Syekh Musthafa meletakkan dasar-dasar pendidikan islam melalui lembaga Pesantren dalam beberpa hal sebagai berikut: (1) kepercayaan terhadap kebenaran ajaran islam (2) kemandirian pada diri sendiri dan tidak tergantung pada orang lain, (3) adanya hubungan dan kerjasama yang baik dengan para ulama dan masyarakat, (4) setiap gagasan dan ketetapan fatwanya dapat diterima masyarakat luas, dan (5) melakukan pengkaderan dan regenerasisasi dengan mengirim lulusan / guru muda belajar ke Mekkah. Kelima faktor pendukung inilah yang selalu terlihat pada perilaku, tindakan dan kegiatan Syekh Musthafa Husein, dan hal ini terlihat pula dalam kehidupan H. Abdullah Musthafa terkecuali faktor kelima, selama memimpin pesantren Musthafawiyah.

Keberadaan pesantren di tengah masyarakat dan di pemerintahan menempati posisi yang membanggakan karena lembaga pendidikan ini telah menjadi simbol bagi masyarakat Mandailing. Dengan dedikasi tinggi dan semangat juang yang ikhlas, kepemimpinan Syekh Musthafa Husein menjadi panutan dan patronase di dalam 
masyarakat, dan juga di kalangan agama pada masa itu. Kegiatan dalam hidupnya telah tercermin dari apa yang dirintisnya, sehingga membawa pengaruh terhadap mayarakat luas. Karena semua itu telah mempengaruhi dan membentuk jati diri seorang Syekh Musthafa Husein. Maka dari itu, Penulis tertarik mengangkat judul "Peran Musthafa Husein Al-Mandili di Pesantren Musthafawiyah Purba Baru 1915-1955”.

Metode penelitian yang digunakan oleh penulis adalah metode sejarah. Metode sejarah memuat petunjuk pelaksanaan dan teknis tentang bahan, kritik, dan interpretasi sejarah serta penyajian sejarah dalam bentuk tulisan (Kuntowijoyo dalam Rahman, 2008: 43). Adapun tahapan dalam metode sejarah terbagi atas empat, yakni Heuristik (pengumpulan sumber), verifikasi (kritik internal dan eksternal terhadap sumber), interpretasi, dan yang terakhir adalah historiografi (penulisan sejarah).

\section{PEMBAHASAN}

Syekh Musthafa Husein Al-Mandili Bin Husein Nasution Bin Umar Nasution AlMandili adalah seorang ulama terkemuka di Sumatera Utara yang meninggalkan karya bangunan keislaman monumental Madrasah di Purba Baru. Saat ini nama Syekh Musthafa Husein diabadikan pada salah satu gedung utama di Universitas Islam Negeri Sumatera Utara.

Syekh Musthafa Huseinlahir di Tano Bato, Kayu Laut pada tahun 1886 M/1303 $\mathrm{H}$ dengan nama kecil Muhammad Yatim dari pasangan $\mathrm{H}$. Husein Nasution dan $\mathrm{Hj}$. Halimah ayahnya seorang saudagar yang taat beragama. Keadaan masyarakat di Tano Bato saat itu sangat menyedihkan akibat perlakuan penjajah Belanda yang memberlakukan sistem tanam paksa bagi para petani.

Di usia 7 tahun, Syehk Musthafa bersekolah di Sekolah Dua, Kayu Laut. Setelah lima tahun tamat dan melanjutkan belajar kepada Syekh Abdul Hamid di Huta Pungkut. Syekh Abdul Hamid merupakan kerabatnya sendiri yang menamatkan pendidikannya di Makkah. Pada Tahun 1900, Syekh Musthafa berkesempatan melanjutkan pendidikann ke Makkah, Saudi Arabia. 
Selama di Makkah beliau berguru kepada ulama-ulama terkemuka, 10 orang di antaranya : Syekh Abdul Qodir Al-Mandily, Syehk Mukhtar Bagan, Syekh Ahmad Sumbawa, Syekh Salih Bafadil, Syekh Ali Maliki, Syekh Umar Bajuneid, Syekh Ahmad Khatib, Syekh Abdul Rahman, Syekh Umar Sato, dan Syekh Muhammad Amin Madinah. Atas bimbingan para ulama terkemuka di atas ditambahkan kecerdasan Syekh Musthafa maka beliau dipercaya gurunya untuk menjadi pengajar di Masjidil Haram. Bidang ilmu utama yang ditekuninya adalah ilmu fikih.

Pada tahun 1912, Syekh Musthafa kembali ke kampung halamannya karena ayahnya meninggal dunia. Syekh Musthafa mulai mengajar dari mesjid ke mesjid di sekitar Tano Bato. Kehadiran beliau dalam mengajarkan Islamdi Tano Bato mendapat sambutan yang baik dari masyarakat, apalagi beliau tetap berpegang teguh dengan mempertahankan Ahlussunnah Wal Jamaah (Aswaja). Hal ini lah yang memberikan pemikiran bagi beliau untuk membuat sebuah wadah dalam mengamalkan dan mengajarkan ilmu yang di perolehnya sampai ke Makkah. Pada tanggal 12 November 1912 beliaupun mendirikan Pondok Pesantren di Tanobato, Kayu Laut (Baharuddin, 2009:5).

Setelah tahun 1934 (setelah melatih sekitar 19 tahun) ia mulai beralih dari melatih ke segi usaha. Ia hanya kadang pergi ke madrasah bagi melihat-lihat serta memberi pemberian pedoman untuk pelaksanaan dan pengawasan. Selanjutnya madrasah banyak dipercayakan bagi kemanakannya yang sekaligus juga kader dan penerusnya yaitu Syekh Abdul Halim Khatib.Dan menantunya Syekh Ja'far Abdul Wahhab Tanjung. Dalam segi usaha ini ia memperluas kebun karet, nenas dan rambutan. Termasuk dalam hal ini pengolahan karet menjadi latex, usaha pengawetan buah dan rencana pengalengannya (khusus usaha buah ini belum sempat terlaksana sebab datangnya serangan Jepang ke daerah Mandailing / Indonesia). Di samping itu ia juga meneruskan usahanya dalam segi perdagangan serta tetap mengadakan pengajian di masjid.

Di dalam edukasi formal ini ia selalu menekankan bagi murid-muridnya untuk hidup mandiri. Petuahnya yang selalu dikenang ialah " tuan kecil " lebih adil dari pada 
jongos besar. Dalam hidup ini ia selalu menekankan tidak boleh berharap banyak pada bantuan dan belas kasihan orang lain, apalagi menginginkan sedekah. Dengan tegas ia merundingkan "baen na tuho, borkatan dei" (usaha sendiri lebih adil dan lebih berkat). Hasil usaha sendiri walaupun kecil lebih adil dari bantuan atau pemberian orang lain, walau bantuan atau pemberian orang lain itu lebih besar,lebih dari pada itu ia juga selalu memberi wejangan (semacam nasehat) bagi murid-muridnya agar setiap ilmu yang diperoleh bagaimanapun sedikitnya supaya diajarkan bagi orang lain. Dalam menempuh hidup ini juga supaya bekerjasama dengan pemerintah maupun pengusaha.Dan bagi setiap tamu supaya dihormati walaupun tamu itu bukan orang Islam.(Hal ini dibuktikannya sendiri dengan menanggapi lawatan orang Belanda ke rumahnya dengan penyambutan yang semarak, diantarnya dengan penyambutan lagulagu pujian yang ungkapan-ungkapannya berbicara Arab. Di samping itu ia juga memuliakan raja-raja daerah yang pada ketika itu banyak yang korup dan tindakantindakannya banyak yang berhadapan dengan ajaran Islam). Ia juga tak mencampuri perkara adat istiadat daerah, ia hanya menjernihkan hukum-hukumnya terserah bagi yang bersangkutan tetap menerapkannya atau menghentikannya. Ia memberi keleluasaan bagi setiap orang.

Di luar dari pada itu ia juga selalu memperhatikan kesulitan orang lain, ia selalu menyempatkan untuk memberi bantuan secara terus maupun melewati orang lain. Setiap orang yang datang meminta bantuan akan dibantunya sekuat tenaga atau sekiranya tak dapat dibantunya, dimintakannya bantuan orang lain (orang ketiga) yang memungkinkan untuki membantunya. (dalam bantuan melewati orang ketiga ini sering yang bersangkutan tak mengetahui bahwa ia mendapat bantuan dari Syekh Musthafa Husein).Ia juga sering mengikuti setiap keramaian yang diadakan oleh publik, baik itu perayaan-perayaan keagamaan berupa Maulid Nabi Muhammad maupun Isra' Mi'rajnya, perkawinan ataupun duka cita. Disamping itu ia juga mengikuti acara-acara keluarga semacam memasuki rumah baru, syukuran maupun tahlilan (dalam bahasa daerah sering dikata mangontang dongan atau marpio malim atau marontang malim). Musthafa Husein juga mengusahakan kader-kader penerus dengan mendorong mereka 
agar memperdalam ilmu-ilmu agama Islam ke sumber aslinya ke Mekkah, saudi Arabia atau negara-negara Islam lainnya. Ia juga membawa ke atas kader-kader itu menjadi anggota keluarganya dengan mengawinkan putri-putrinya atau putri saudaranya bagi kader-kader yang telah dibinanya itu. Hal itu semua diterapkannya bagi memperkembangkan petuah dan syi'ar Islam bagi seluruh masyarakat, terutama masyarakat Mandailing Natal, Sumatera Utara, Indonesia. (Sirajuddin, 2011:48).

Syekh Mustahafa Husein adalah seorang tokoh dan ulama besar di Sumatera Utar yang menginginkan umat Islam maju sehingga umat Islam itu dapat bersaing dengan bangsa-bangsa lain baik diberbagai bidang kehidupan seperti di bidang politik, ekonomi, dan di ilmu pengetahuan, untuk terwujudnya hal tersebut maka yang dilakukan Syekh Musthafa Husein adalah meningkatkan mutu pendidikan Islam dan mamacu umat Islam agar dapat bersaing dengan bangsa lain dalam berbagai bidang yang dibutuhkan untuk kemajuan dan kesejahteraan masyarakat Islam. Salah satu contohnya adalah kontribusi pemikiran Syekh Musthafa Husein yang berharga bagi masyarakat di bidang politik yaitu dalam upanya Syekh Musthafa Husein dalam menyiarkan Islam beliau membentuk organisasi persatuan pelajar-pelajar dangan nama Al-Ittidaiyah Islamiyah Indonesia (AII) organisasi ini pada tahun 1936 berpusat di Purba Baru, selanjutnya jauh sebelum pendirian organisasi beliau juga pernah memasuki organisasi Syarekat Islam yang tujuannya untuk mencerdaskan bangsa dan menanamkan kesadaran kepada masyarakat bahwa salah satu tugas Islam untuk membebaskan manusia dari kebodohan, keterbelakangan dan kemiskinan.

Pada tahun 16 Nopember 1955, Syekh Musthafa Husein Nasution menghembuskan nafas terakhir di Padang Sidimpuan dan di makamkan di Purba Baru. Setelah kepergian Syekh Musthafa, Musthafawiyah di kelola dan dipimpin oleh putra tertuanya, $\mathrm{H}$. Abdullah Musthafa Nasution. Saat ini Musthafawiyah dikelola dan dipimpin oleh cucu Syekh Musthafa yang bernama H. Musthafa Bakri Nasution.

Setelah Syeikh Musthafa Husein meninggal dunia pada tahun 1955, tampak kepandaian di teruskan oleh anaknya Syeikh Abdullah Bin Musthafa bin Husein Nasution, di bawah kemahirannya dalam memimpin, Pondok Musthafawiyah menjadi 
tambah berkembang pesat, ini juga tak jauh dari usaha menantu Syeikh Musthafa Husein Syeikh Abdul Halim Khatib Lubis Al-Mandaili sebagai Ra`is Al-Mu`allimin pesantren tersebut, ia pernah menimba ilmu di Shalatiyah Makkah dan Masjidil Haram, salah satu gurunya ia merupakan Syeikh Qadhi Hasan Masaath Al-Makki, dan adapun teman untuk berlatih ketika di Makkah merupakan Syeikh Yasin Al-Fadani dan Syeikh Zakariya bin Abdullah Bila Batu bara, Muhammad Zainuddin Al-Ampenani, Syekh Adnan Lubis.Ia memiliki sebuah karya tulis berbahasa melayu, yang disimpan di Purba Baru, ia wafat pada tahun 1991.

Pada tahun 1915 Syekh Musthafa Husein mengalami hambatan yang sangat sulit dikarenakan terjadi bencana banjir sangat besar yang menghanyutkan rumahrumah penduduk di Tano Bato sehingga pada tanggal 25 Nopember 1915 Syekh Musthafa hijrah ke Purba Baru. Seorang muridnya yang bernama Abdul Halim Lubis ikut hijrah dari Tanobato ke Purba Baru. Abdul Halim Lubis ikut hijrah dari Tanobato ke Purba Baru.

Di Desa Purba Baru Musthafa Husein belum sepenuhnya melakukan aktifitas seperti mengajar dengan baik di karenakan lokal-lokal yang digunakan sebagai tempat belajar belum memadai, sehingga Musthafa Husein lebih banyak menghabiskan waktunya di Mesjid dan di Surau untuk mengajari murid-muridnya. Mengingat murid semakin banyak masyarakat mulai mengibahkan tanah untuk dibuat lokal yang baru

Di samping itu salah satu hambatan di pesantren musthafawiyah yaitu sulitnya mendapat air bersih, hal ini dikarenakan di lokasi pesantren hanya terdapat sedikit sumber air, hanya satu sungai yang mengalir di Desa Purba Baru disitulah hampir seluruh para pokir (anak santri laki-laki) melakukan kegiatan baik mandi dan aktifitas lainnya. Dan beliau juga sering ke Mekkah untuk menuntut ilmu yang lebih dalam lagi, sehingga murid beliau dititipkan kepada orang yang bisa mengganti Musthafa Husein untuk mengajari murid-murid selama beliau di Mekkah, masa beliau ini juga masih sedikit tanah yang akan di bangun lokal-lokal baru,dan keadaan tanahnya yang berbukit-bukit sehingga sulit untuk membangun lokal. Bahkan hingga sekarang pun gedung-gedungnya terpisah karna tanahnya berbentuk bukit-bukit itu. 


\section{KESIMPULAN}

Syekh Musthafa Husein Al-Mandili Bin Husein Nasution Bin Umar Nasution Al-Mandili adalah seorang ulama terkemuka di Sumatera Utara yang meninggalkan karya bangunan keislaman monumental Madrasah di Purba Baru. Saat ini nama Syekh Musthafa Husein diabadikan pada salah satu gedung utama di Universitas Islam Negeri Sumatera Utara.Syekh Musthafa Huseinlahir di Tano Bato, Kayu Laut pada tahun 1886 M/1303 H dengan nama kecil Muhammad Yatim dari pasangan H. Husein Nasution dan $\mathrm{Hj}$. Halimah ayahnya seorang sodagar yang taat beragama. Keadaan masyarakat di Tano Bato saat itu sangat menyedihkan akibat perlakuan penjajah Belanda yang memberlakukan sistem tanam paksa bagi para petani.

Kontribusi pemikiran Syekh Musthafa Husein kepada masyarakat desa Purba Baru daapat dilihat dari berbagai bidang seperti bidang politik Syekh Musthafa Husein pernah mengajarkan dan melakukan tata cara berpolitik sehingga beliau berhaasil memenangkan konstitusi pemilihan DPR unttuk wilayah Sumatera Utara, Beliau juga menetapkan standar pengetahuan bagi seorang pemimpin yaitu harus memahami isi kitab I'anati at-thalibin.

Pada tahun 1915 Syekh Musthafa Husein mengalami hambatan yang sangat sulit dikarenakan terjadi bencana banjir sangat besar yang menghanyutkan rumahrumah penduduk di Tanobato sehingga pada tanggal 25 Nopember 1915 Syekh Musthafa hijrah ke Purba Baru. Seorang muridnya yang bernama Abdul Halim Lubis ikut hijrah dari Tanobato ke Purba Baru. Abdul Halim Lubis ikut hijrah dari Tanobato ke Purba Baru.

Diluar daripada itu salah satu hambatan di pesantren musthafawiyah yaitu sulitnya mendapat air bersih,dikarenakan lokasi pesantren ini tidak banyak sumber air, hanya satu sungai yang mengalir di desa Purba Baru disitulah hampir seluruh para pokir (anak santri laki-laki) melakukan kegiatan baik mandi dan aktifitas lainnya. Dan beliau juga sering ke Mekkah untuk menuntut ilmu yang lebih dalam lagi, sehingga murid 
beliau di titipkan kepada orang yang bisa mengganti Mustafha Husein untuk mengajari murid-murid selama beliau di Mekkah

Dalam kepemimpinan Syekh Musthafa Husein Nasution dimulai dari tahun 1912-1955 dengan jumlah santri 450 orang dan sarana / prasarana 9 lokal. Setelah Syekh Musthafa Husein meninggal, Kepemimpin Pondok Pesantren Musthafawiyah diwariskan kepada anak dan cucunya yaitu : 1) Kepemimpinan Pesantren Musthafawiyah Purba Baru dilanjutkan oleh anaknya yang bernama H.Abdullah Musthafa Nasution. Di masa kepemimpinan H. Abdollah Musthafa Nasution Pondok Pesantren Musthafawiyah Purba Baru mengalami kemajuan yang sangat pesat dengan jumlah santri 8.500 orang dari tahun 1955-1995, 2) Setelah H. Abdullah Musthafa Nasution meninggal dunia estafet kepemimpinan Pondok Pesantren Musthawaiyah Purba Baru dilanjutkan oleh adik kandung beliau Drs. H. Abdul Kholik Nasution yang juga merupakan putra Syekh Musthafa Husein Nasution Pendiri Pondok Pesantren Musthafawiyah Purba Baru, dan beliau memimpin Pondok Pesantren Mustfawiyah Purba Baru mulai tahun 1955-2003 dengan jumlah santri 6.300 orang, 3) Kepemimpinan Pondok Pesantren Musthafawiyah Purba Baru dilanjutkan oleh cucu Syekh Musthafa Husein yaitu H. Mustafa Bakri Nasution yang merupakan putra dari H. Abdollah Musthafa Nasution, pada tahun 2003 sampai sekarang dengan jumlah santri 11.501 orang. Beliau mengikuti jejak ayahandanya yaitu dengan berusaha semaksimal mungkin untuk melanjutkan pembangunan Pondok Pesantren Musthafawiyah Purba Baru di segala bidang. 


\section{REFERENSI}

Abdullah, Sani, Ridwan. 2011. Pendidikan Karakter di Pesantren. Bandung: Citapustaka Media Perintis

Arif, Mohammad. 2013. Perkembangan Pesantren Di Era Teknologi. STAIN Tulungagung. Jurnal Penelitian Perkembangan Pesantren Vol. XXVIII No. 2 2013/1434

Baharuddin Nasution, dkk. 2009. Riwayat Hidup Almarhum Syekh Musthafa Husein Purba Baru (1886-1955). Mandailing Natal: Pondok Pesantren Musthafawiyah Purba Baru

Bani, Suddin. 2015. Kontribusi Pesantren Dalam Sistem Pendidikan Nasional. Fakultas Tarbiyah dan Keguruan UIN Alauddin MakassarAuladuna, Vol. 2 No. 2 Desember 2015: 264-273

Daulay, Putra Haidar. 2018. Sejarah Pertumbuhan dan Pembaruan Pendidikan Islam di Indonesia. Jakarta: Prenada Media Group

Dhofier, Zamakhsyari. 2011. Tradisi Pesantren Studi Pandangan Hidup Kyai dan Visinya Mengenai Masa Depan Indonesia. Jakrta Barat: LP3ES

Editor M. Dawan Rahardjo, dkk. 1988. Pesantren dan Pembaharuan. Jakarta: LP3ES

Ferdinan. Pondok Pesantren, Ciri Khas Perkembangannya. Pendidikan Agama Islam Fakultas Agama Islam Unismuh Makassar. Jurnal Tarbawi Volume 1 No 1 ISSN 2527-4082

Galbu, Sindu. 1995. Pesantren sebagai Wadah Konunikasi.Jakarta: Rineka Cipta

Hamdan Mansoer, dkk. 2004. Materi Instruksional Pendidikan Agama Islam di Perguruan Tinggi Umum. Jakarta: Direktorat Perguruan Tinggi Agama Islam Departemen Agama RI

Https://www.alkhoirot.net/2011/09/pondok-pesantren-musthafawiyah-purba.html (Di akses pada tanggal 05 Agustus 2019 pukul 11.31)

Lubis, Purnama. 2017. Kontribusi Pemikiran Syekh Musthafa Husein Terhadap Teologi Masyarakat Desa Purba Baru Kecamatan Lembah Sorik Marapi. Pascasarjana Universitas Islam Negeri Sumatera Utara MedanAl-Lubb, Vol. 2, No. 1, 2017: 1-18 
Nizar, Samsul. 2016. Sejarah Pendidikan Islam Menelusuri Jejak Sejarah Pendidikan Era Rasulullah Sampai Indonesia. Jakarta: Prenada Media Group

Pondok Pesantren Muthafawiyah Purba Baru. 2016. Propil Pondok Pesantren Musthafawiyah Purba Baru Kabupaten Mandailing Natal

Pulungan, Abbas. 2012. Riwayat Singkat Syekh Musthafa Husein, Syekh Abdul Halim Khatib, dan Haji Abdullah Musthafa Pendiri,Pewaris, dan Penerus Kharisma dan Keilmuan Islam Di Pesantren Musthafawiyah Purba Baru. Medan: Perdana Publishing

Sirajuddin, Abbas K.H (2011). Ulama Syafi'i dan Kitab-Kitabnya dari Zaman ke Zaman. Jakarta, Indonesia: Pustaka Tarbiyah. ISBN 978-979-26-4317-6.

Steenbrink, Karel A. 1986. Pesantren Madrasah Sekolah: Pendidikan Islam dalam Kurun Moderen. Jakarta: LP3ES.

Suwendi. 2004. Sejarah Pemikiran Pendidikan Islam. Jakarta: PT. Raja Grapindo Persada

Syafe'i, Imam. 2017. Pondok Pesantren: Lembaga Pendidikan Pembentukan Karakter. Universitas Islam Negeri Raden Intan Lampung. Al-Tadzkiyyah: Jurnal Pendidikan Islam, Volume 8, Mei 2017. P. ISSN: 20869118, E-ISSN: 2528-247

Yasmadi. 2002. Modernisasi Pesantren: Kritik Nurcholis Madjid terhadap Pendidikan Islam Tradisional. Jakarta: Ciputat Press. 